UMTRI-2004-22

\title{
OPTIMAL STRATEGIES FOR ADAPTIVE CURVE LIGHTING
}

\author{
Michael Sivak \\ Brandon Schoettle \\ Michael J. Flannagan \\ Takako Minoda
}

August 2004 
OPTIMAL STRATEGIES FOR ADAPTIVE CURVE LIGHTING

Michael Sivak Brandon Schoettle Michael J. Flannagan

Takako Minoda

The University of Michigan Transportation Research Institute Ann Arbor, Michigan 48109-2150 U.S.A.

Report No. UMTRI-2004-22

August 2004 
Technical Report Documentation Page

\begin{tabular}{|c|c|}
\hline $\begin{array}{l}\text { 1. Report No. } \\
\text { UMTRI-2004-22 }\end{array}$ & 3. Recipient's Catalog No. \\
\hline \multirow[t]{2}{*}{$\begin{array}{l}\text { 4. Title and Subtitle } \\
\text { Optimal Strategies for Adaptive Curve Lighting }\end{array}$} & $\begin{array}{l}\text { 5. Report Date } \\
\text { August } 2004\end{array}$ \\
\hline & $\begin{array}{l}\text { 6. Performing Organization Code } \\
302753\end{array}$ \\
\hline $\begin{array}{l}\text { 7. Author(s) } \\
\text { Sivak, M., Schoettle, B., Flannagan, M.J., and Minoda, T. }\end{array}$ & $\begin{array}{l}\text { 8. Performing Organization Report No. } \\
\text { UMTRI-2004-22 }\end{array}$ \\
\hline \multirow{2}{*}{$\begin{array}{l}\text { 9. Performing Organization Name and Address } \\
\text { The University of Michigan } \\
\text { Transportation Research Institute } \\
\text { 2901 Baxter Road } \\
\text { Ann Arbor, Michigan } 48109-2150 \text { U.S.A. }\end{array}$} & 10. Work Unit no. (TRAIS) \\
\hline & 11. Contract or Grant No. \\
\hline \multirow{2}{*}{$\begin{array}{l}\text { 12. Sponsoring Agency Name and Address } \\
\text { The University of Michigan } \\
\text { Industry Affiliation Program for } \\
\text { Human Factors in Transportation Safety }\end{array}$} & 13. Type of Report and Period Covered \\
\hline & 14. Sponsoring Agency Code \\
\hline
\end{tabular}

The Affiliation Program currently includes AGC America, Autoliv, Automotive Lighting, Avery Dennison, BMW, DaimlerChrysler, DBM Reflex, Denso, Federal-Mogul, Ford, GE, General Motors, Gentex, Guide Corporation, Hella, Honda, Ichikoh Industries, Koito Manufacturing, Lang-Mekra North America, Magna International, Mitsubishi Motors, Muth, Nichia America, Nissan, North American Lighting, OLSA, OSRAM Sylvania, Philips Lighting, PPG Industries, Reflec USA, Reflexite, Renault, Samlip, Schefenacker International, Sisecam, Solutia Performance Films, Stanley Electric, TG North America, Toyota Technical Center USA, Valeo, Vidrio Plano, Visteon, 3M Personal Safety Products, and 3M Traffic Safety Systems.

Information about the Affiliation Program is available at: http://www.umich.edu/ industry/

16. Abstract

This analytical study evaluated the advantages and disadvantages of several curvelighting strategies that involved moving one or both low beams by various amounts. Two curve radii were examined $(80 \mathrm{~m}$ and $240 \mathrm{~m}$ ) for both curve directions (left and right). Recent market-weighted median U.S. and ECE tungsten-halogen low beam patterns, and a recent median U.S. HID beam pattern were used. Seven lateral positions were of interest, corresponding to the lane of travel and the left adjacent lane, and additional lanes of travel to the left and right or off-road objects. The dependent variable was the maximum distance of 3-lux illumination (combined from both lamps) at a plane $0.25 \mathrm{~m}$ above the roadway.

The main findings for the short-radius curves were: (1) All of the examined curvelighting strategies tended to perform substantially better than the nominal aim. (2) The improved performance for given lateral positions in the visual field tended not to be coupled with worsened performance for other lateral positions of interest. (3) The differences among the curve-lighting strategies were small. (4) The best strategy involved moving both lamps in parallel by $15^{\circ}$ into the curve.

The main findings for the large-radius curves were: (1) The best strategy depended on the curve direction, beam pattern, and lateral position in the visual field. (2) There were performance trade-offs between left and right lateral positions (especially for the right curve), with improvements in one lateral area generally being paired with decrements in the other.

In conclusion, for short-radius left and right curves, moving both lamps in parallel should substantially increase the visibility of objects in one's lane of travel, in several additional lanes of travel to the left and right, and off the road. Thus, implementing such a curve-lighting strategy is recommended for small-radius curves. On the other hand, because of the lateral trade-offs of benefits and costs for large-radius curves, additional research is needed to better understand the desirable approach for these types of curves. Finally, because of the inherent lateral asymmetry of low beams, future research should also further explore the benefits of asymmetric shifts for left and right curves.

17. Key Words

adaptive lighting, curve lighting, AFS, low beams, passing beams, benefits, visibility, seeing, HID, tungsten halogen, U.S., Europe, ECE

\begin{tabular}{|c|c|c|l|}
\hline $\begin{array}{c}\text { 19. Security Classification (of this report) } \\
\text { None }\end{array}$ & $\begin{array}{c}\text { 20. Security Classification (of this page) } \\
\text { None }\end{array}$ & $\begin{array}{c}\text { 21. No. of Pages } \\
23\end{array}$ & 22. Price \\
\hline
\end{tabular}




\section{Acknowledgment}

Appreciation is extended to the members of the University of Michigan Industry Affiliation Program for Human Factors in Transportation Safety for support of this research. The current members of the Program are:

AGC America
Autoliv
Automotive Lighting
Avery Dennison
BMW
DaimlerChrysler
DBM Reflex
Denso
Federal-Mogul
Ford
GE
General Motors
Gentex
Guide Corporation
Hella
Honda
Ichikoh Industries
Koito Manufacturing
Lang-Mekra North America
Magna International
Mitsubishi Motors
Muth

Nichia America

Nissan

North American Lighting

OLSA

OSRAM Sylvania

Philips Lighting

PPG Industries

Reflec USA

Reflexite

Renault

Samlip

Schefenacker International

Sisecam

Solutia Performance Films

Stanley Electric

TG North America

Toyota Technical Center, USA

Valeo

Vidrio Plano

Visteon

3M Personal Safety Products

3M Traffic Safety Systems 


\section{Contents}

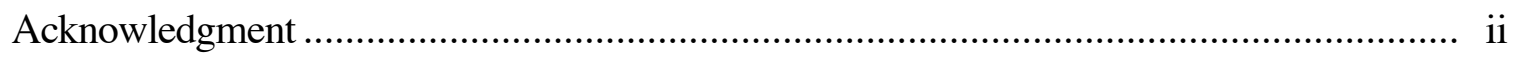

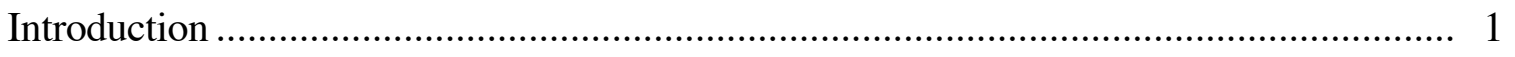

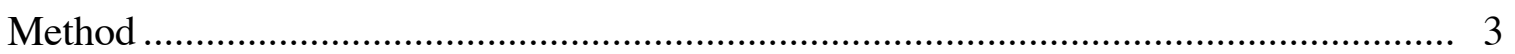

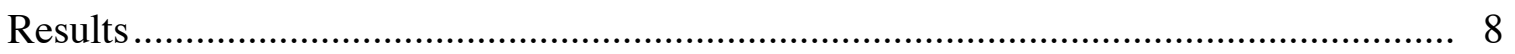

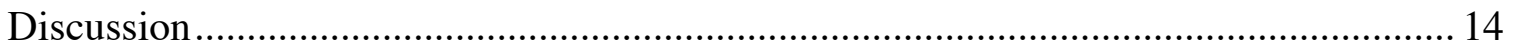

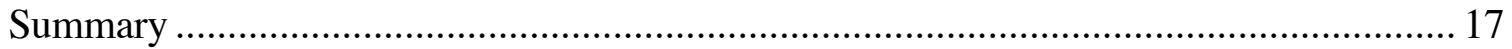

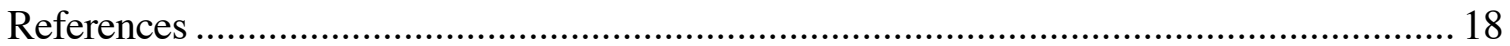




\section{Introduction}

Dynamically controllable headlamp illumination is not a new concept. Headlamps that turned in response to movement of the steering wheel were already available in the late 1920s (e.g., the Pilot-Ray system), and were installed in the now famous 1948 Tucker automobile. Modern, more complex versions of dynamically controllable headlamp illumination are usually referred to as adaptive or intelligent headlamp systems. The Lucas Autosensa (Jones and Hicks, 1970) was probably the first advanced adaptive headlighting system built in a prototype series, but it was never implemented (Rumar, 1997).

The late 1980s and early 1990s saw a major revival of interest in adaptive lighting, especially in Japan (e.g., Wada, Miyazawa, Yagi, Takahashi, and Shibata, 1989; Kobayashi and Hayakawa, 1991; Sivak, Flannagan, Traube, Aoki, and Sayer, 1994; Gotoh and Aoki, 1996; and Aoki, Kitamura, Miyagawa, and Kaneda, 1997). The next phase of increased research into adaptive lighting started in Europe with a Eureka Project called AFS (Advanced Frontlighting Systems). (See AFS, 1994 and 1996, for early AFS documents.) The original AFS plans called for adaptive lighting for the following six specific situations: curves, motorways, adverse weather, overhead traffic signs, country roads, and towns.

The AFS approach that has gathered the most commercial interest is curve lighting. It involves, in some embodiments, only horizontal or vertical displacements of a given base beam pattern. Specifically, in these embodiments, curve lighting (also called bending or swiveling light) involves controlling the horizontal aim of the beam pattern (or a part of it), depending on variables such as the radius of the curve and the speed of the vehicle. There are several possible strategies for implementing curve lighting, including moving both lamps in tandem, moving both lamps but each to a different extent, moving only one of the lamps, moving lamps differentially on left and right curves, or energizing additional lamps (e.g., Hamm, 2002; Hara, Kuramochi, Ayama, Kojima, and Sato, 2001; Hogrefe, 2000; Ishiguro and Yamada, 2004; Löwenau, Strob, Bernasch, Reich, and Rummel, 2001; McLaughlin, Hankey, Green, and Larsen, 2004; Neumann, 2004; Strambersky, Cejnek, and Martoch, 2004; von Hoffmann, 2001; Yamamoto, 2004).

We examined the potential benefits of applying curve lighting to the U.S. and ECE low-beam patterns in a recent analytical study (Sivak, Flannagan, Schoettle, and Nakata, 2001). The curve lighting simulations paired 80 -m radius left and right curves with a horizontal beam shift of $15^{\circ}$ (for both lamps), and 240-m radius curves with a shift of $10^{\circ}$ (again for both lamps). Changes in both visibility and glare illuminance were considered. Market-weighted model year 2000 U.S. and ECE beam patterns were used. We concluded that curve lighting, as simulated in that study, would (1) substantially improve seeing 
performance on curves for both types of beams; (2) lead to an increase in disability glare on left curves (but not on right curves); and (3) create no major discomfort-glare problems.

In Sivak et al. (2001) we evaluated the visibility provided by different systems by comparing the amount of illumination directed towards selected important points in space. These points represented pedestrians on the right edgeline of the lane of travel at 50 and $100 \mathrm{~m}$; pedestrians on the left edgeline of the left adjacent lane at 50 and $100 \mathrm{~m}$; right shoulder-mounted, center overhead, and left shoulder-mounted traffic signs at $150 \mathrm{~m}$; vehicle rear-reflex reflectors at $20 \mathrm{~m}$; and a target at the road expansion point.

The present study is a direct follow-up to Sivak et al. (2001). There are four major extensions to the previous study. Specifically, in the present study we (1) examined the changes in the reach of low beams when curve lighting is applied to the U.S. and European low beams, (2) compared several different implementations of curve lighting, (3) considered wider lateral positions that encompass more lanes of travel and off-road objects, and (4) used an updated European tungsten-halogen market-weighted beam pattern, as well as both tungsten-halogen and HID U.S. beam patterns. 


\section{Method}

\section{General approach}

In our simulations of the benefits of applying curve lighting to the different beam patterns, we used two different fixed-radius curves (representing two different speed scenarios), and we applied different combinations of horizontal shifts to the beam pattern of the left and right lamps (and of different magnitudes for each curve radius). Of interest was the amount of the combined illuminance from the left and right lamps at a height of $0.25 \mathrm{~m}$ above the road surface (corresponding, for example, to the lower legs of pedestrians). The dependent variable was the maximum distance where this illumination reached 3 lux (the approximate dark bound of civil twilight). Seven lateral locations were considered: the right edgeline of the lane of travel, and the right edgelines of four lanes to the left and two lanes to the right of the lane of travel.

In addition to simulating multiple-lane scenarios, the outside lanes also represent potential locations of off-road objects. For example, assuming a two-lane roadway, the two lateral locations to the right of the lane of travel and the two outermost locations to the left of the lane of travel represent four different lateral offsets for off-road objects. The width of each lane was set at $3.7 \mathrm{~m}$. The headlamp mounting height was set at $0.66 \mathrm{~m}$ and lamp separation at $1.20 \mathrm{~m}$ (Schoettle, Sivak, and Nakata, 2002).

Figure 1 presents an illustration of the basic approach. It shows a bird's-eye view of a two-lane roadway, with two additional lanes to the right and left. Lane lines 1 and 2 will be referred to as the left positions; lane lines 3, 4, and 5 as the center positions; and lane lines 6 and 7 as the right positions. Superimposed on the roadway scene is the 3-lux isoilluminance line (derived by combining the illuminance from both headlamps) at a height of $0.25 \mathrm{~m}$ above the roadway. The distances of the intercepts of the 3-lux line with the lane lines were of primary interest. For some lane lines (lines 3 through 7 in Figure 1), the illuminance did, indeed, reach 3 lux at a certain distance. On the other hand, for other lane lines (lines 1 and 2 in Figure 1), the illuminance never reached 3 lux. 


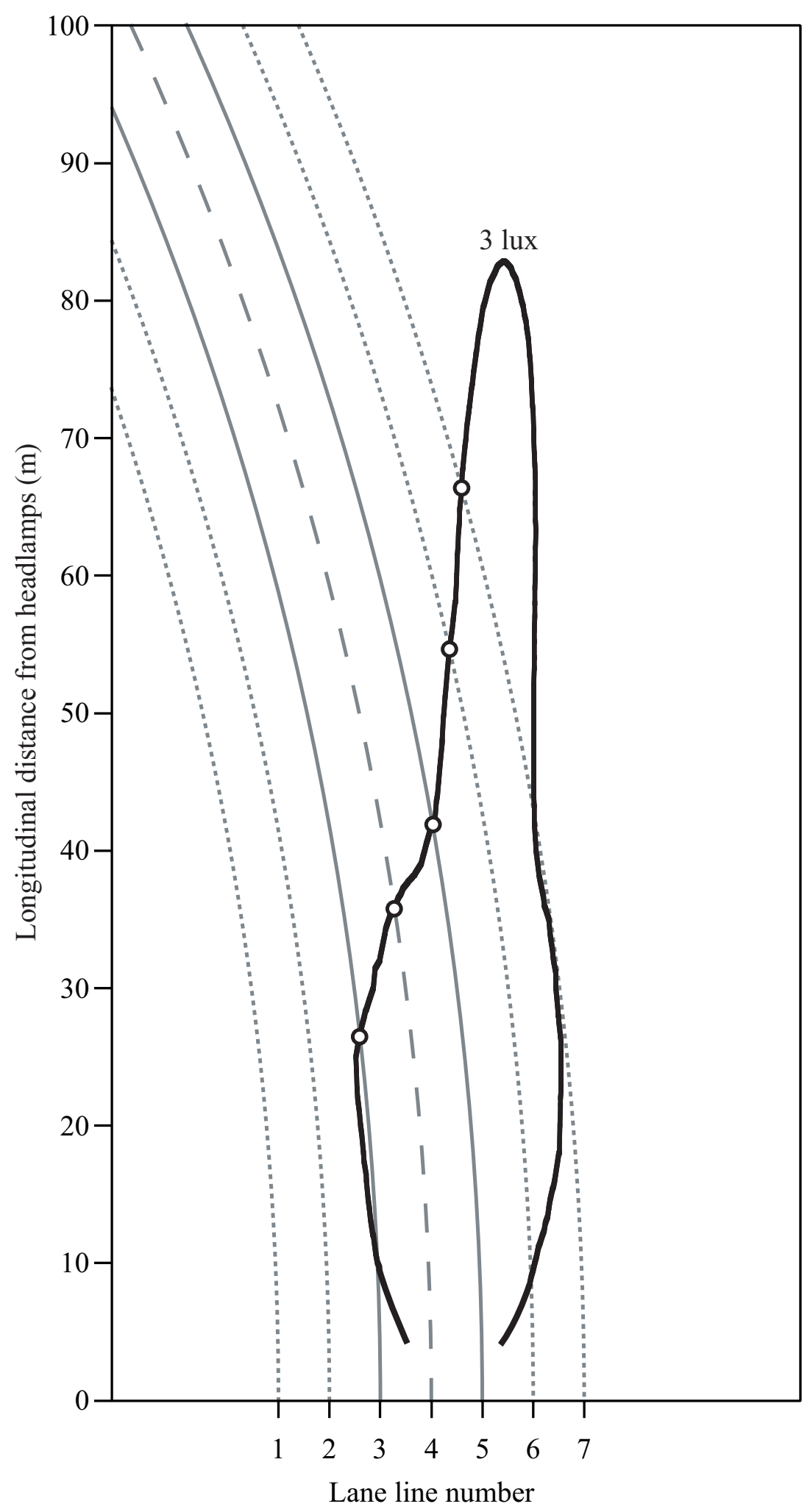

Figure 1. A schematic diagram of the seven lane lines along with a superimposed 3-lux isoilluminance line at a height of $0.25 \mathrm{~m}$ above the roadway. In this example, the illuminance never reaches 3 lux for lane lines 1 and 2. (The vehicle was centered between lane lines 4 and 5.) 


\section{Curve scenarios and beam-pattern shifts}

For the low-speed scenario, we used a curve with a constant radius of $80 \mathrm{~m}$, and applied the horizontal shifts shown in Table 1 (also shown schematically in Figure 2). For the high-speed scenario, we used a curve with a constant radius of $240 \mathrm{~m}$, and applied the horizontal shifts shown in Table 2. Both right curves and left curves were considered. By comparison, for a headlamp-mounting height of $0.66 \mathrm{~m}$ (as was the case in this study), SAE specifies a maximum shift of $35.3^{\circ}$ for an $80-\mathrm{m}$ radius curve and $11.1^{\circ}$ for a $240-\mathrm{m}$ radius curve (SAE, 2002). The corresponding ECE maxima are $24.4^{\circ}$ and $7.9^{\circ}$ (ECE, 2003).

Table 1

Horizontal shifts of the beam patterns for the 80 -m radius curves.

\begin{tabular}{|l|c|c|}
\hline \multicolumn{1}{|c|}{ Strategy } & Inner lamp & Outer lamp \\
\hline \hline Nominal & $0^{\circ}$ & $0^{\circ}$ \\
\hline Parallel & $15^{\circ}$ & $15^{\circ}$ \\
\hline Crossing & $7.5^{\circ}$ & $15^{\circ}$ \\
\hline Diverging & $15^{\circ}$ & $7.5^{\circ}$ \\
\hline Inner only & $15^{\circ}$ & $0^{\circ}$ \\
\hline Outer only & $0^{\circ}$ & $15^{\circ}$ \\
\hline
\end{tabular}

Table 2

Horizontal shifts of the beam patterns for the 240-m radius curves.

\begin{tabular}{|l|c|c|}
\hline \multicolumn{1}{|c|}{ Strategy } & Inner lamp & Outer lamp \\
\hline \hline Nominal & $0^{\circ}$ & $0^{\circ}$ \\
\hline Parallel & $7.5^{\circ}$ & $7.5^{\circ}$ \\
\hline Crossing & $3.75^{\circ}$ & $7.5^{\circ}$ \\
\hline Diverging & $7.5^{\circ}$ & $3.75^{\circ}$ \\
\hline Inner only & $7.5^{\circ}$ & $0^{\circ}$ \\
\hline Outer only & $0^{\circ}$ & $7.5^{\circ}$ \\
\hline
\end{tabular}




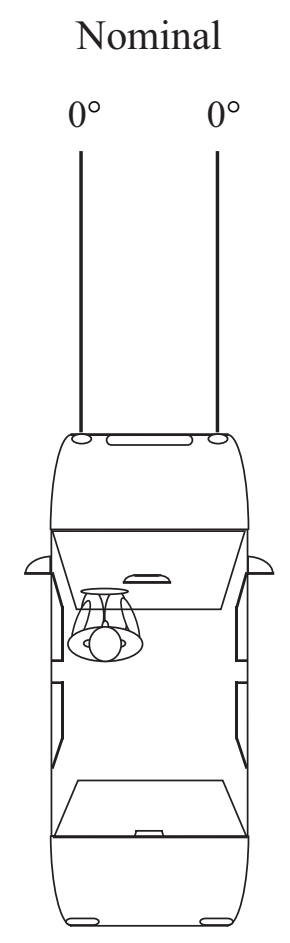

Crossing

Inner only
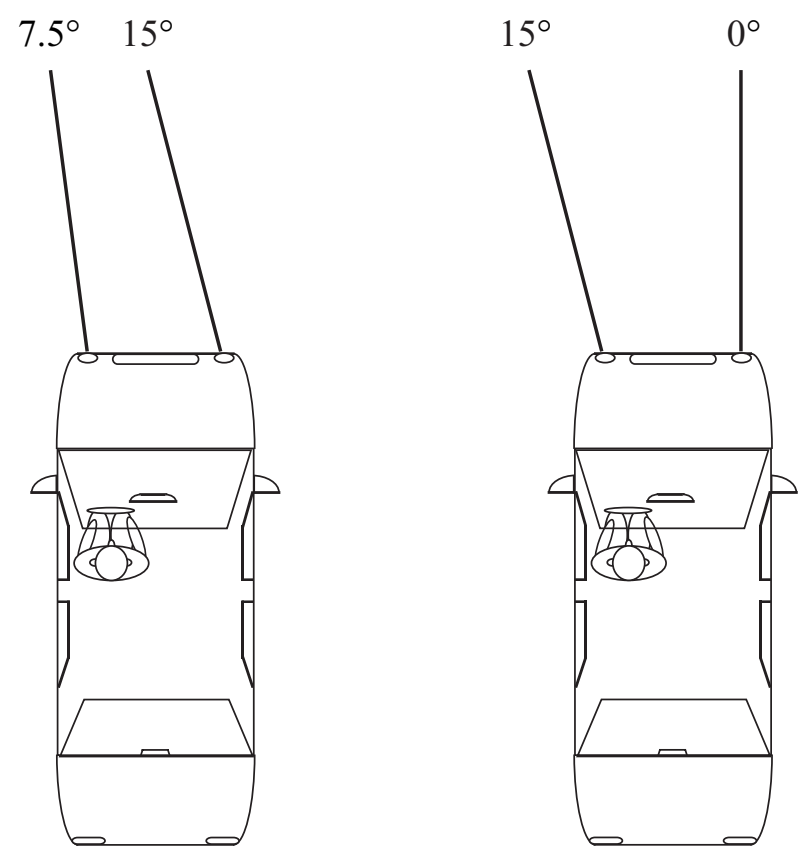

Parallel

Diverging

Outer only
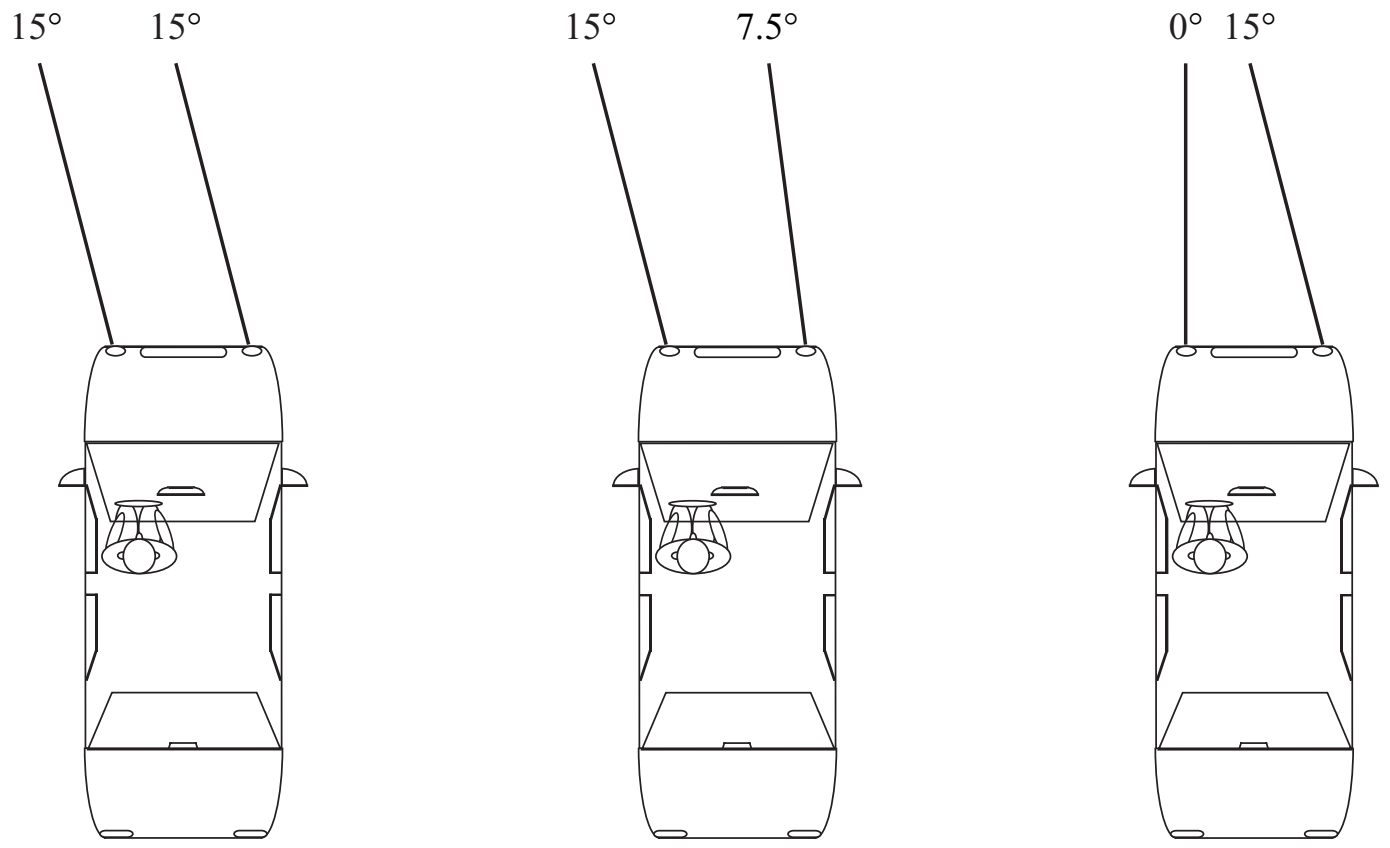

Figure 2. A schematic representation of the horizontal shifts of the beam patterns for the tested curve-lighting strategies on an 80-m radius left curve. 


\section{Beam patterns}

Three different beam patterns were used: (1) Median market-weighted model year 2001 U.S. tungsten-halogen low beams from Schoettle, Sivak, and Flannagan (2001), (2) median model year 2000 U.S. HID low beams from Sivak, Flannagan, Schoettle, and Nakata (2002), and (3) median market-weighted model year 2003 European tungstenhalogen low beams from Schoettle, Sivak, Flannagan, and Kosmatka (2003). 


\section{Results}

The basic results - the maximum distances at which the illuminance reached 3 lux - are shown in Figures 3 through 6 . The main findings will be discussed by the curves investigated.

\section{0-m left curve (Figure 3)}

(1) All curve lighting strategies tended to yield longer reach than the nominal aim.

(2) Moving both lamps in parallel produced the best results, but the differences among the curve-lighting strategies were small (except when using the ECE lamps).

(3) For the right-most position with the ECE lamps, moving only one of the two lamps did not increase the reach.

(4) For the left-most position, the illuminance did not reach 3 lux for any lamp type with any of the curve-lighting strategies.

(5) The results for the U.S. tungsten-halogen and HID lamps followed similar patterns.

\section{0-m right curve (Figure 4)}

(1) All curve lighting strategies tended to yield longer reach than the nominal aim. The exceptions to this pattern were the left positions: Here moving only the inner or outer lamp resulted in worse performance than the nominal aim, but for the European lamps these were the only two strategies that at least eventually reached 3 lux.

(2) The best strategy involved moving both lamps in parallel.

(3) The differences among the strategies were smaller for the U.S. lamps than for the ECE lamps.

(4) Although the results for the U.S. tungsten-halogen and HID lamps followed similar patterns, the HID lamps consistently yielded longer reach. 


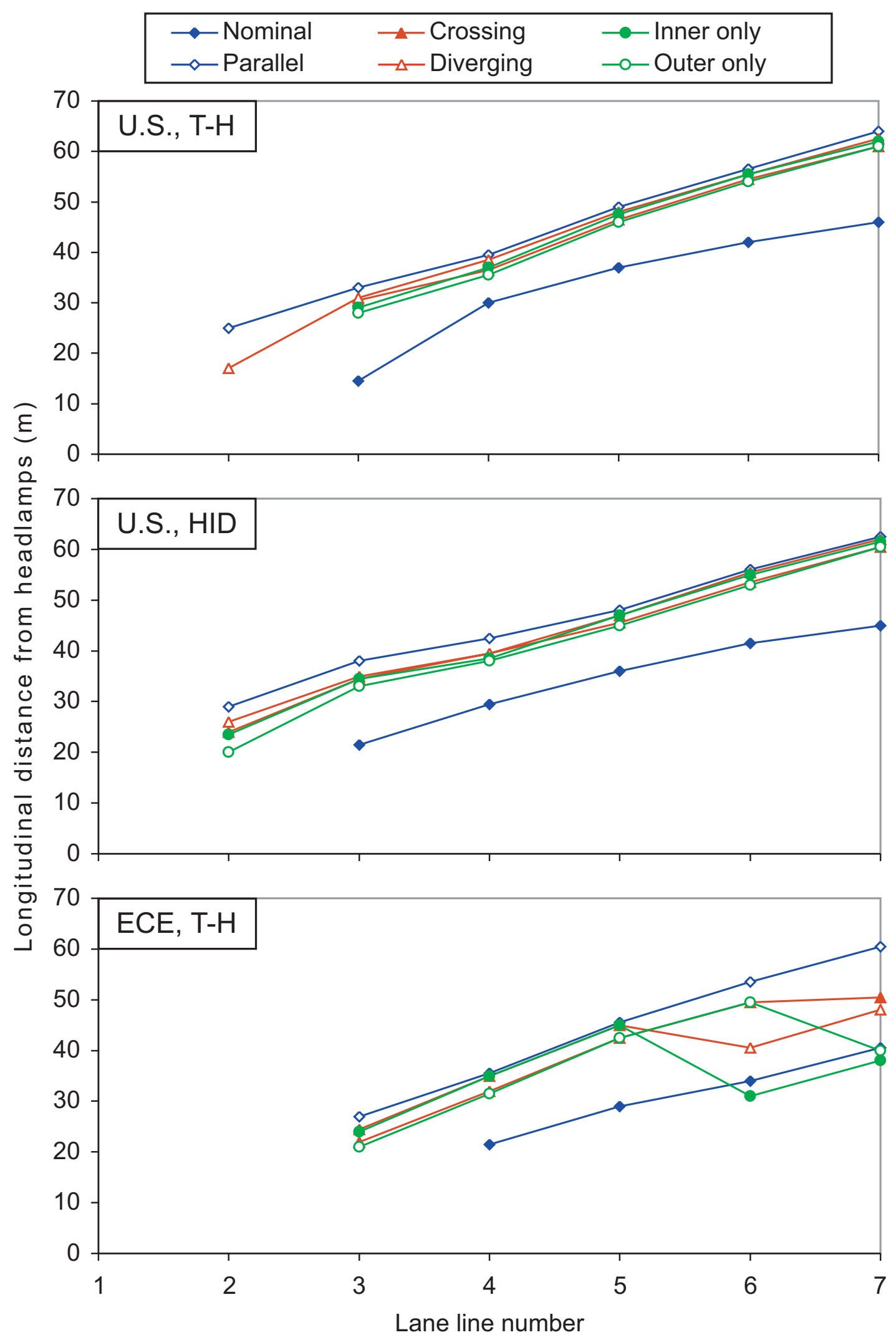

Figure 3. The maximum reach of the 3-lux line for the 80-m radius left curve. 


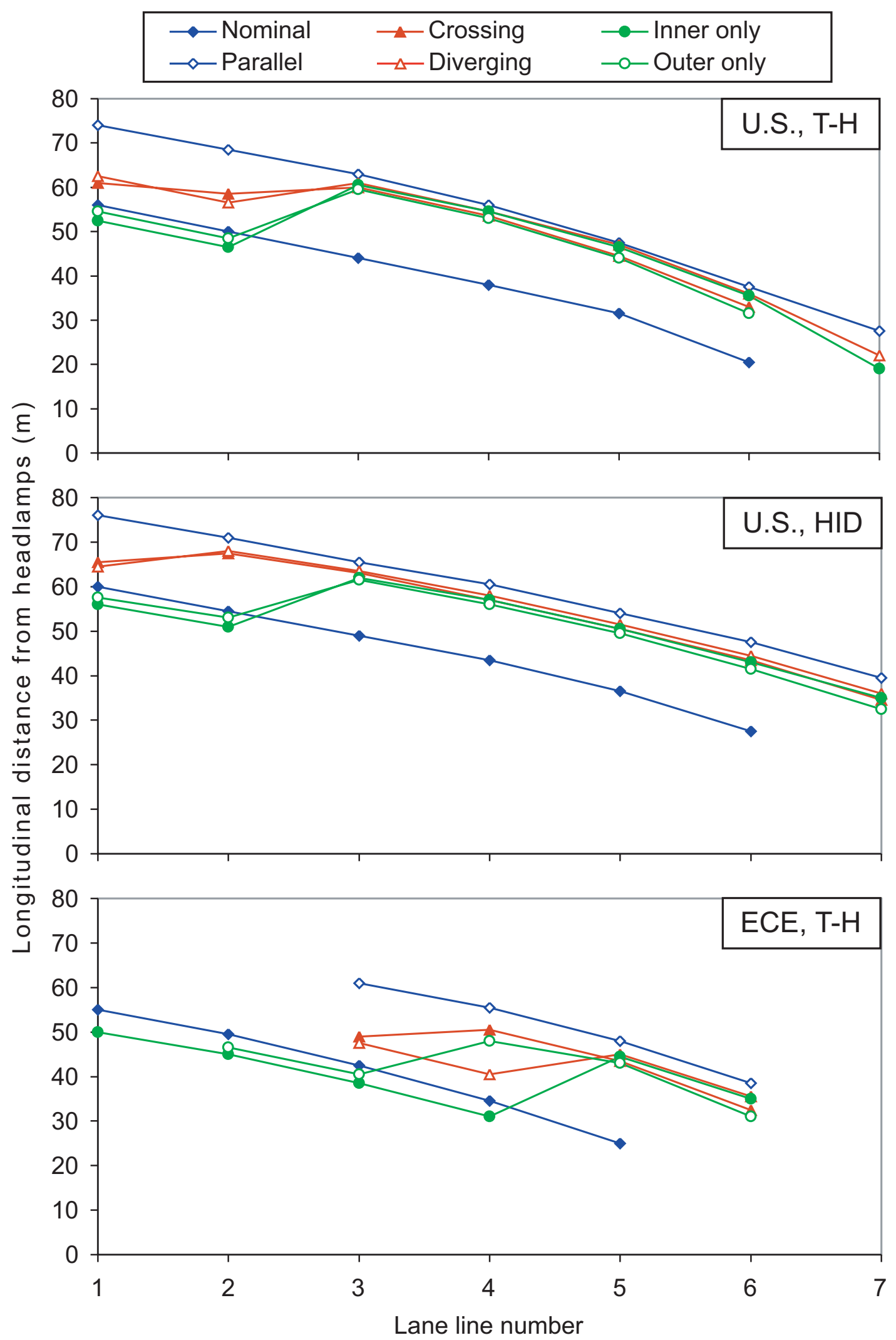

Figure 4. The maximum reach of the 3-lux line for the 80-m radius right curve. 


\section{0-m left curve (Figure 5)}

(1) For the center and left positions, all curve lighting strategies yielded longer reach than the nominal aim. Moving both lamps in parallel was best, but the differences among the strategies were small.

(2) For the right positions, the best strategy was lamp- and position-dependent. For example, for the U.S. tungsten-halogen lamps and lane line 6, the longest reach was achieved by the parallel strategy; for lane line 7, the nominal aim was best, followed by the two strategies that involved moving only one lamp (with the other strategies never achieving 3 lux).

(3) For the left-most position, the illuminance for neither lamp type reached 3 lux with any of the curve-lighting strategies.

(4) The curve lighting strategies using U.S. HID lamps, in comparison to the U.S. tungsten-halogen lamps, were especially effective at the right-most position tested.

\section{0-m right curve (Figure 6)}

(1) The curve-lighting strategies improved the reach for the right positions, with the parallel strategy being best.

(2) For the left positions, the best performance was achieved by the nominal aim. In other words, here none of the curve lighting strategies matched the nominal aim in the reach of the 3-lux line.

(3)For the center positions, the best strategy depended on the particular combination of lamp type and specific position.

(4) The curve-lighting strategies using U.S. HID lamps, in comparison to the U.S. tungsten-halogen lamps, tended to be more effective at the right positions. 


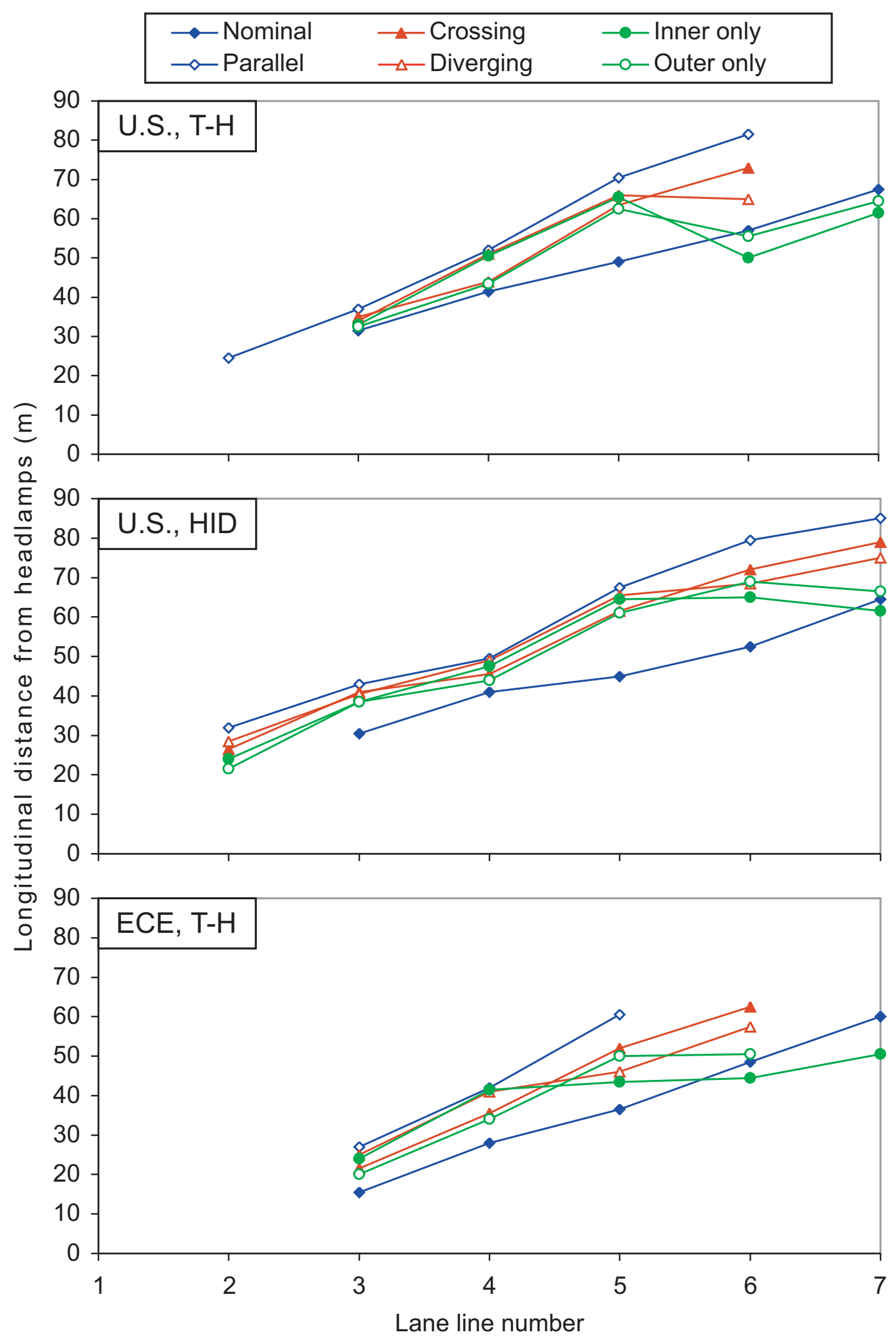

Figure 5. The maximum reach of the 3-lux line for the 240-m radius left curve. 


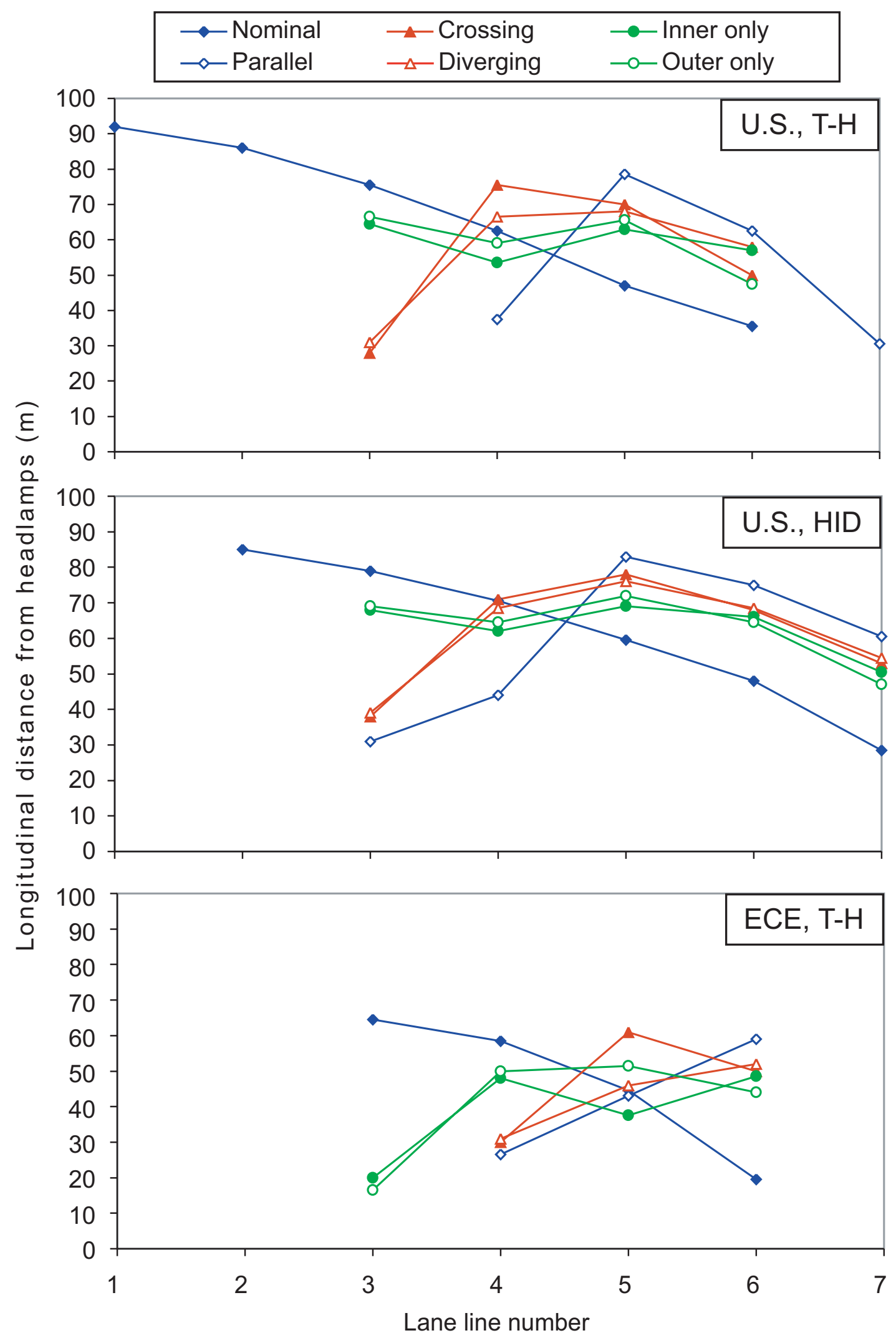

Figure 6. The maximum reach of the 3-lux line for the 240-m radius right curve. 


\section{Discussion}

\section{General considerations}

Although the differences among the strategies were frequently small, there were several consistent trends. The best strategies, as a function of curve radius, curve direction, lamp type, and lateral position, are summarized in Table 3.

For the 80-m radius, left curve, the results were consistent across all variables of interest: The best curve-lighting strategy involved moving both lamps in parallel. That was also the case for the 80-m radius, right curve, except for the left positions when using ECE tungsten-halogen lamps. For this combination, the best performance was obtained using the nominal aim.

For the 240-m radius, left curve, the parallel strategy was best for the left and center positions, but that was not the case for the right-most position. Specifically, shifting both lamps by $7.5^{\circ}$ to the left caused the right-most position to be less well illuminated than under the nominal aim (except for the U.S. HID lamps). An analogous lateral trade-off was also evident for the 240-m radius, right curve. Here, the parallel strategy was best for the right positions, but for the left positions the best strategy was the nominal aim.

Table 3

The best strategies by curve radius, curve direction, lamp type, and lateral position.

\begin{tabular}{|l|c|c|c|c|}
\hline \multirow{2}{*}{$\begin{array}{c}\text { Curve radius, } \\
\text { curve direction }\end{array}$} & \multirow{2}{*}{ Lamp } & \multicolumn{3}{|c|}{ Lateral position } \\
\cline { 3 - 5 } & & Left & Center & Right \\
\hline \hline \multirow{3}{*}{$80 \mathrm{~m}$, left } & U.S.: T-H & Parallel & Parallel & Parallel \\
\cline { 2 - 5 } & U.S.: HID & Parallel & Parallel & Parallel \\
\cline { 2 - 5 } & ECE: T-H & Parallel & Parallel & Parallel \\
\hline \multirow{3}{*}{$80 \mathrm{~m}$, right } & U.S.: T-H & Parallel & Parallel & Parallel \\
\cline { 2 - 5 } & U.S.: HID & Parallel & Parallel & Parallel \\
\cline { 2 - 5 } & ECE: T-H & Nominal & Parallel & Parallel \\
\hline \multirow{3}{*}{$240 \mathrm{~m}$, left } & U.S.: T-H & Parallel & Parallel & Parallel/nominal \\
\cline { 2 - 5 } & U.S.: HID & Parallel & Parallel & Parallel \\
\cline { 2 - 5 } & ECE: T-H & Parallel & Parallel & Crossing/nominal \\
\hline & U.S.: T-H & Nominal & Parallel/crossing/nominal & Parallel \\
\cline { 2 - 5 } & U.S.: HID & Nominal & Parallel/nominal & Parallel \\
\cline { 2 - 5 } & ECE: T-H & Nominal & Crossing/nominal & Parallel \\
\hline
\end{tabular}




\section{Moving both lamps in parallel}

The performance of the leading candidate - the parallel strategy - is compared quantitatively to the nominal aim in Table 4. Specifically, Table 4 lists the changes in the reach of the 3-lux line as a function of curve radius, curve direction, lamp type, and lateral position. One important aspect of the information in Table 4 is that there were large benefits of the parallel strategy for many conditions of interest. For example, for the right edgeline of the lane of travel (lane line 5), the benefits were present for 11 out of 12 combinations of the conditions tested, with a maximum added reach of $31.5 \mathrm{~m}$.

Table 4

Change in reach (in meters) of the 3-lux line for the parallel strategy, compared to the nominal aim, by curve radius, curve direction, lamp type, and lateral position (lane line). Positive entries favor the parallel strategy, while negative entries favor the nominal aim.

\begin{tabular}{|l|c|c|c|c|c|c|c|c|}
\hline \multirow{2}{*}{$\begin{array}{l}\text { Curve radius, } \\
\text { curve direction }\end{array}$} & \multirow{2}{*}{ Lamp } & \multicolumn{7}{|c|}{ Lane line } \\
\cline { 2 - 9 } & & 1 & 2 & 3 & 4 & 5 & 6 & 7 \\
\hline \hline \multirow{3}{*}{$80 \mathrm{~m}$, left } & U.S., T-H & $*$ & + & 18.5 & 9.5 & 12.0 & 14.5 & 18.0 \\
\cline { 2 - 9 } & U.S., HID & $*$ & + & 16.5 & 13.0 & 12.0 & 14.5 & 17.5 \\
\cline { 2 - 9 } & ECE, T-H & $*$ & $*$ & + & 14.0 & 16.5 & 19.5 & 20.0 \\
\hline \multirow{3}{*}{80 m, right } & U.S., T-H & 18.0 & 18.5 & 19.0 & 18.0 & 16.0 & 17.0 & + \\
\cline { 2 - 9 } & U.S., HID & 16.0 & 16.5 & 16.5 & 17.0 & 17.5 & 20.0 & + \\
\cline { 2 - 9 } & ECE, T-H & - & - & 18.5 & 21.0 & 23.0 & + & $*$ \\
\hline \multirow{3}{*}{240 m, left } & U.S., T-H & $*$ & + & 5.5 & 10.5 & 21.5 & 24.5 & - \\
\cline { 2 - 9 } & U.S., HID & $*$ & + & 12.5 & 8.5 & 22.5 & 27.0 & 20.5 \\
\cline { 2 - 9 } & ECE, T-H & $*$ & $*$ & 11.5 & 14.0 & 24.0 & - & - \\
\hline & U.S., T-H & - & - & - & -25.0 & 31.5 & 27.0 & + \\
\cline { 2 - 9 } & U.S., HID & $*$ & - & -48.0 & -26.5 & 23.5 & 27.0 & 32.0 \\
\cline { 2 - 8 } & ECE, T-H & $*$ & $*$ & - & -32.0 & -1.5 & 39.5 & + \\
\hline
\end{tabular}

+ The nominal aim never reached 3 lux, i.e., there was an improvement in performance with the parallel strategy.

- The parallel strategy never reached 3 lux, i.e., there was a decrement in performance with the parallel strategy.

* Neither the nominal aim nor the parallel strategy reached 3 lux.

However, directing a portion of the limited amount of illumination to certain relevant areas of the visual field can result in a decrement in illumination in other relevant areas. This is primarily evident for the 240 -m radius, right curve. Here, the general gains in reach for the parallel strategy for positions 5, 6, and 7 were offset by losses for positions 
1 through 4. An analogous, but less pronounced pattern was also present for the left curve when using either the U.S. or ECE tungsten-halogen lamps. For those conditions, the gains in the left and center positions were offset by the losses at the right-most position. No similar tradeoffs were present for either of the two 80-m radius curves (with the exception of the 80-m, right curve when using the ECE lamps).

\section{Having your cake and eating it too?}

The preceding considerations highlight an important aspect of any curve lighting strategy that relies on redistribution of a given amount of illumination (as opposed to providing additional illumination): The benefits of such curve-lighting strategies depend on the region of the visual field where illumination is to be augmented, and on other region(s) where decreases in illumination can be tolerated. If the exclusive concern is with illuminating the lane of travel and the left adjacent lane (the most important parts of the driver's visual field), then major improvements can be achieved on left and right shortradius curves and left large-radius curves by many of the strategies investigated, with the best strategy involving moving both lamps in parallel. Furthermore, for the short radius curves, the general pattern for the parallel strategy was that the benefits in this area were generally not offset by losses in the left or right peripheral areas representing objects on additional adjacent lanes or off-road targets.

However, as discussed above, a more complex pattern was evident for the largeradius curves studied. Here, none of the curve-lighting strategies produced benefits for all lateral positions studied. This was especially evident for the large-radius, right curve. Here, providing more illumination for the right positions with the parallel strategy was accompanied by decrements in illumination for the center and left positions.

\section{Strategies for left and right curves}

Low beam patterns are, inherently, laterally asymmetric. This is a consequence of trying to minimize the glare for oncoming drivers. Consequently, as has been discussed by Yamamoto (2004), optimal curve-lighting strategies might turn out to be different for left and right curves. Further research in this area is recommended. 


\section{Summary}

This analytical study evaluated the advantages and disadvantages of several curvelighting strategies that involved moving one or both low beams by various amounts. Two curve radii were examined $(80 \mathrm{~m}$ and $240 \mathrm{~m}$ ) for both curve directions (left and right). Recent market-weighted median U.S. and ECE tungsten-halogen low beam patterns, and a recent median U.S. HID beam pattern were used. Seven lateral positions were of interest, corresponding to the lane of travel and the left adjacent lane, and additional lanes of travel to the left and right or off-road objects. The dependent variable was the maximum distance of 3-lux illumination (combined from both lamps) at a plane $0.25 \mathrm{~m}$ above the roadway.

The main findings for the short-radius curves were: (1) All of the examined curvelighting strategies tended to perform substantially better than the nominal aim. (2) The improved performance for given lateral positions in the visual field tended not to be coupled with worsened performance for other lateral positions of interest. (3) The differences among the curve-lighting strategies were small. (4) The best strategy involved moving both lamps in parallel by $15^{\circ}$ into the curve.

The main findings for the large-radius curves were: (1) The best strategy depended on the curve direction, beam pattern, and lateral position in the visual field. (2) There were performance trade-offs between left and right lateral positions (especially for the right curve), with improvements in one lateral area generally being paired with decrements in the other.

In conclusion, for short-radius left and right curves, moving both lamps in parallel should substantially increase the visibility of objects in one's lane of travel, in several additional lanes of travel to the left and right, and off the road. Thus, implementing such a curve-lighting strategy is recommended for small-radius curves. On the other hand, because of the lateral trade-offs of benefits and costs for large-radius curves, additional research is needed to better understand the desirable approach for these types of curves. Finally, because of the inherent lateral asymmetry of low beams, future research should also further explore the benefits of asymmetric shifts for left and right curves. 


\section{References}

AFS (Advanced Frontlighting Systems). (1994). EUREKA Project 1403, Part 1 - Project Information Amsterdam, Holland: EUREKA.

AFS (Advanced Frontlighting Systems). (1996). EUREKA Project 1403, Phase 1 Feasibility Study, Final Report. Amsterdam, Holland: EUREKA.

Aoki, T., Kitamura, H., Miyagawa, K., and Kaneda, M. (1997). Development of active headlight system (SAE Technical Paper Series No. 970650). Warrendale, PA: Society of Automotive Engineers.

ECE [Economic Commission for Europe]. (2003). Uniform provisions concerning the approval of vehicles with regard to the installation of lighting and light-signalling devices (Regulation No. 48). Geneva: United Nations.

Gotoh, S., and Aoki, T. (1996). Development of active headlight. Presented at the 15th International Conference on the Enhanced Safety of Vehicles, Melbourne, Australia.

Hamm, M. (2002). Adaptive lighting functions history and future-Performance investigations and field test of user acceptance (SAE Technical Paper Series No. 2002-01-0526). Warrendale, PA: Society of Automotive Engineers.

Hara, T., Kuramochi, T., Ayama, M., Kojima, S., and Sato, T. (2001). Evaluation of AFS from driver's point of view. In, Progress in Automobile Lighting (pp. 397-402). Darmstadt, Germany: Technical University of Darmstadt.

Hogrefe, H. (2000). Adaptive frontlighting systems for optimum illumination of curved roads, highway lanes and other driving situations (SAE Technical Paper Series No. 2000-01-0431). Warrendale, PA: Society of Automotive Engineers.

Ishiguro, K. and Yamada, Y. (2004). Control technology for bending mode AFS (SAE Technical Paper Series No. 2004-01-0441). Warrendale, PA: Society of Automotive Engineers.

Jones, K.J., and Hicks, H.V. (1970). The Lucas Autosensa. Technical aspects of road safety, 41, 4.1-4.13.

Kobayashi, S., and Hayakawa, M. (1991). Beam controllable headlighting system (SAE Technical Paper Series No. 910829). Warrendale, PA: Society of Automotive Engineers.

Löwenau, J.P., Strob, M.H., Bernasch, J.H., Reich, F.M., and Rummel, A.H. (2001). Evaluation of adaptive light control in the BMW driving simulator. In, Proceedings of the 2001 Driving Simulation Conference (CD ROM). Arcueil, France: INRETS. 
McLaughlin, S., Hankey, J., Green, C.A., and Larsen, M.K. (2004). Target detection distances and driver performance with swiveling HID headlamps (SAE Technical Paper Series No. 2004-01-2258). Warrendale, PA: Society of Automotive Engineers.

Neumann, R. (2004). AFS halogen headlamp system: Experimental study and first field results (SAE Technical Paper Series No. 2004-01-0439). Warrendale, PA: Society of Automotive Engineers.

Rumar, K. (1997). Adaptive illumination systems for motor vehicles: Towards a more intelligent headlighting system (Report No. UMTRI-97-7). Ann Arbor: The University of Michigan Transportation Research Institute.

SAE [Society of Automotive Engineers] (2002). Adaptive forward lighting system (Surface Vehicle Recommended Practice J2591). Warrendale, PA: Society of Automotive Engineers.

Schoettle, B., Sivak, M., and Flannagan, M.J. (2001). High-beam and low-beam headlighting patterns in the U.S. and Europe at the turn of the millennium (Report No. UMTRI-2001-19). Ann Arbor: The University of Michigan Transportation Research Institute.

Schoettle, B., Sivak, M., Flannagan, M.J., and Kosmatka, W.J. (2003). A market-weighted description of low-beam headlighting patterns in Europe: 2003 (Report No. UMTRI-2003-37). Ann Arbor: The University of Michigan Transportation Research Institute.

Schoettle, B., Sivak, M., and Nakata, Y. (2002). The locations of signaling and lighting equipment on passenger vehicles sold in the U.S. (Report No. UMTRI-2002-8). Ann Arbor: The University of Michigan Transportation Research Institute.

Sivak, M., Flannagan, M.J., Schoettle, B., and Nakata, Y. (2001). Benefits of applying adaptive lighting to the U.S. and European low-beam patterns (Report No. UMTRI-2001-20). Ann Arbor: The University of Michigan Transportation Research Institute.

Sivak, M., Flannagan, M.J., Schoettle, B., and Nakata, Y. (2002). Performance of the first generation of HID headlamps in the U.S. (Report No. UMTRI-2002-14). Ann Arbor: The University of Michigan Transportation Research Institute.

Sivak, M., Flannagan, M.J., Traube, E.C., Aoki, M., and Sayer, J.R. (1994). Evaluation of an active headlight system (Report No. UMTRI-1994-17). Ann Arbor: The University of Michigan Transportation Research Institute. 
Strambersky, L., Cejnek, M., and Martoch, J. (2004). Fast Track-Static and dynamic bending analysis (SAE Technical Paper Series No. 2004-01-0440). Warrendale, PA: Society of Automotive Engineers.

von Hoffmann, A. (2001). Evaluation of adaptive light distributions with AFSim (SAE Technical Paper Series No. 2001-01-0303). Warrendale, PA: Society of Automotive Engineers.

Wada, K., Miyazawa, K., Yagi, S., Takahashi, K., and Shibata, H. (1989). Steerable forward lighting system (SAE Technical Paper Series No. 890682). Warrendale, PA: Society of Automotive Engineers.

Yamamoto, I. (2004). AFS light distribution control (SAE Technical Paper Series No. 2004-01-0438). Warrendale, PA: Society of Automotive Engineers. 